\title{
QUALIDADE E EDUCAÇÁO A DISTÂNCIA: DO REFERENCIAL TEÓRICO À SUA PROPOSIÇÃO
}

\author{
QUALITY AND DISTANCE EDUCATION: FROM THE THEORETICAL \\ FRAMEWORK TO ITS PROPOSITION
}

\author{
Daniela da Costa Britto Pereira Lima \\ Doutora em Políticas Públicas, Estratégias e Desenvolvimento, \\ Universidade Federal de Goiás - UFG. Goiânia, Goiás - Brasil. \\ ORCID: https://orcid.org/0000-0002-1075-2113 \\ daniela_lima@ufg.br
}

Kátia Morosov Alonso Doutora em Educação, Universidade Federal de Mato Grosso, UFMT. Cuiabá, Mato Grosso - Brasil. ORCID: https://orcid.org/0000-0002-7125-664X katia.ufmt@gmail.com

\begin{abstract}
Resumo: Este estudo possui como objetivo geral identificar características, necessidades, problemas e fatores fundamentais da educação a distância $(\mathrm{EaD})$, da qualidade de um modo geral e, especificamente, da qualidade na educação superior a distância. A pesquisa, do tipo bibliográfica e documental, utilizou a abordagem qualitativa de coleta de dados em documentos elaborados no período 2009 e 2017, e foi realizada em repositórios nacionais e internacionais. Os resultados permitiram construir uma lente teórico-conceitual acerca da $\mathrm{EaD}$ na educaçáo superior $(\mathrm{ES})$ e de sua qualidade, além de contribuir para a elaboração das dimensões e indicadores dessa oferta, em níveis meso e micro de qualidade, favorecendo o empoderamento dos atores interessados e colaborando para a formação de sua agenda política, social e acadêmica.
\end{abstract}

Palavras-chave: Qualidade Social. Educaçáo superior e a distância. Indicadores.

Aвstract: This study aims to identify features, needs, problems and fundamental factors of distance education (DE), quality in general and, specifically, quality in distance higher education. The research, of bibliographic and documentary type, used the qualitative approach to data collection in documents elaborated between 2009 and 2017, and was carried out in national and international repositories. The results allowed to construct a theoretical-conceptual lens about $\mathrm{DE}$ in higher education (HE) and its quality, besides contributing with the elaboration of dimensions and indicators at meso and micro quality level for this offer, favoring the empowerment of the interested actors and contributing in the formation of its political, social and academic agenda.

KEYwORDs: Social quality. Higher education and distance education. Indicators. 


\section{Introduçáo}

Este estudo faz parte de pesquisa de pós-doutorado desenvolvida entre os anos de 2018 e 2019, e busca, a partir de levantamento bibliográfico, estabelecer uma lente teórico-conceitual sobre a qualidade na educação a distância. Tem como base os conceitos de qualidade social, e sua análise e desenvolvimento contemplam dimensôes e indicadores de níveis meso e micro.

Aprofundar um estudo acerca da qualidade da educação superior e a distância justifica-se por três elementos fundamentais: (i) a expansão vertiginosa e privatista da modalidade; (ii) a mudança acelerada da (des) regulamentação da EaD no Governo Temer (2016-2018); (iii) a contribuição para o alcance da meta 12 do Plano Nacional de Educação (2014-2024). Com relação ao item (i), a expansão vertiginosa e privatista da modalidade entre 2002 e 2016 viu o número de matrículas na EaD saltar de 40.714 para 1.494.418 (BRASIL, 2002; 2016). Porém, se em 2002 havia mais matrículas na esfera pública (34.322 contra 6.392 da privada), em 2016 houve uma inversão nesse quadro, com a predominância da esfera privada (1.371.817 contra 122.601 das públicas).

No que diz respeito ao item (ii), assistiu-se durante o Governo Temer educação superior e a distância; à edição da Portaria MEC no 11/2017, que estabelece o seu credenciamento e oferta; resoluçóes que dispóem sobre a oferta de cursos de pós-graduação stricto sensu em EaD, dentre outras. Todas essas legislaçôes póem em risco a qualidade da oferta de cursos a distância e o seu papel na democratizaçáo do ensino com qualidade (OLIVEIRA; LIMA, 2018). Finalmente, o item (iii) ressalta a importância da contribuição da modalidade para elevar, com qualidade, a taxa bruta da matrícula na educação superior em $50 \%$, conforme previsto na meta 12 do PNE.

Considerando, portanto, a multidimensionalidade do termo qualidade e o impacto da regulação sobre ela, este estudo procura explicitar o sentido e a dimensão da qualidade de $\mathrm{EaD}$ na $\mathrm{ES}$ e como se estabelece a sua intencionalidade, pensando no desafio de propor indicadores. Neste artigo, a qualidade é entendida para além do que é determinado pelos organismos multilaterais, reafirmando-se princípios de que educação é 
bem público, direito social e dever do Estado, sendo compreendida em sua dimensão social e pública, garantindo a democratização do acesso e permanência de estudantes em cursos EaD (DIAS SOBRINHO, 2010).

O presente texto está estruturado em três seçôes: a primeira trata da metodologia utilizada para o levantamento bibliográfico; a segunda cuida do sentido e da intencionalidade da educação superior a distância; e, por fim, a terceira que traça uma lente teórico-conceitual de qualidade na $\mathrm{EaD}$, propondo dimensóes e indicadores em nível meso e micro, segundo uma perspectiva de qualidade social, levando em conta o levantamento realizado.

\section{Levantamento bibliográfico, corpus da pesquisa e sistematizaçáo dos dados}

O levantamento bibliográfico foi realizado em seis (6) repositórios nacionais - Biblioteca Digital Brasileira de Teses e Dissertações (BDTD), Catálogo de Teses e Dissertações da Coordenação de Aperfeiçoamento de Pessoal de Nível Superior (Capes), Portal de Periódicos Capes, Anais dos Encontros Nacionais da Associação Nacional de Pós-Graduaçáo e Pesquisa em Educação (ANPEd) e Anais dos Simpósios Brasileiro da Associação Nacional de Política e Administração da Educação (Anpae) - e em quatro (4) internacionais - Scientific Eletronic Library Online (Scielo), Repositórios Científicos de Acesso Aberto de Portugal (RCAAP), Dipòsit Digital de Documents de La UAB/ Universidade Autônoma de Barcelona/ DDD/UAB Espanha e ERIC (Education Resources Information Center).

A ANPEd e a Anpae representam as duas maiores associaçóes da área da pesquisa em educação no Brasil e seus respectivos sites abrigam trabalhos que tratam da $\mathrm{EaD}$ e de sua qualidade separadamente. Apesar disso, nenhum dos 84 trabalhos encontrados no site da Anpae foi selecionado como material desta pesquisa, enquanto no da ANPEd foram considerados apenas dois (2) de um total de 23 artigos. Em alguns repositórios não foi possível selecionar os trabalhos por serem pagos e de acesso restrito, o que, com certeza, prejudica e limita a pesquisa científica.

Estabeleceu-se o período de 2009 a 2017 para a coleta dos materiais/ trabalhos, combinando os termos de busca por meio do operador booleano 
"AND" entre os descritores, pois esperava-se que aqueles que seriam selecionados para a busca deveriam estar presentes em todos os artigos, restringindo a amplitude da pesquisa. A busca usou os descritores "educação a distância AND qualidade AND indicadores" para os repositórios nacionais e dois grupos de descritores para os repositórios internacionais: "distance education AND quality AND indicator AND e-learning"; "educación a distancia AND e-learning AND calidad AND indicator". Apesar de o período da pesquisa ter 2017 como ano limite, foram considerados alguns trabalhos de 2018 que apareceram nas buscas por conta de sua relevância.

Em suma, foram encontrados 1.021 trabalhos e, desses, selecionados 81, com a seguinte distribuição:

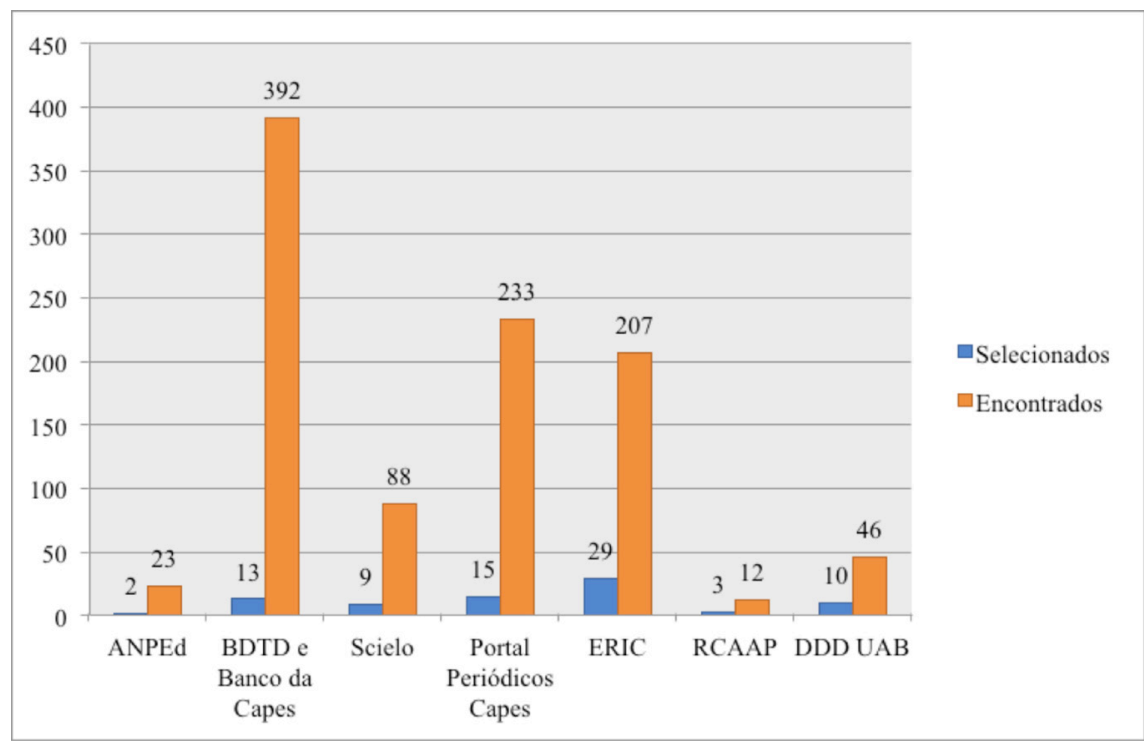

Figura 1: Número de trabalhos selecionados por repositório pesquisado Fonte: Elaborado pelas autoras, com base no levantamento bibliográfico.

Observa-se que os 343 repositórios do BDTD e os 49 do Banco de Teses e Dissertaçóes da Capes (49) apresentaram juntos o maior número de trabalhos selecionados e em português, enquanto o ERIC trouxe o maior número de trabalhos selecionados e, em sua maioria, publicados em 
inglês. Entre todos os trabalhos, foram selecionados 35 em português e 46 em inglês e espanhol juntos. $\mathrm{O}$ gráfico da Figura 2 a seguir mostra os tipos de trabalhos encontrados.

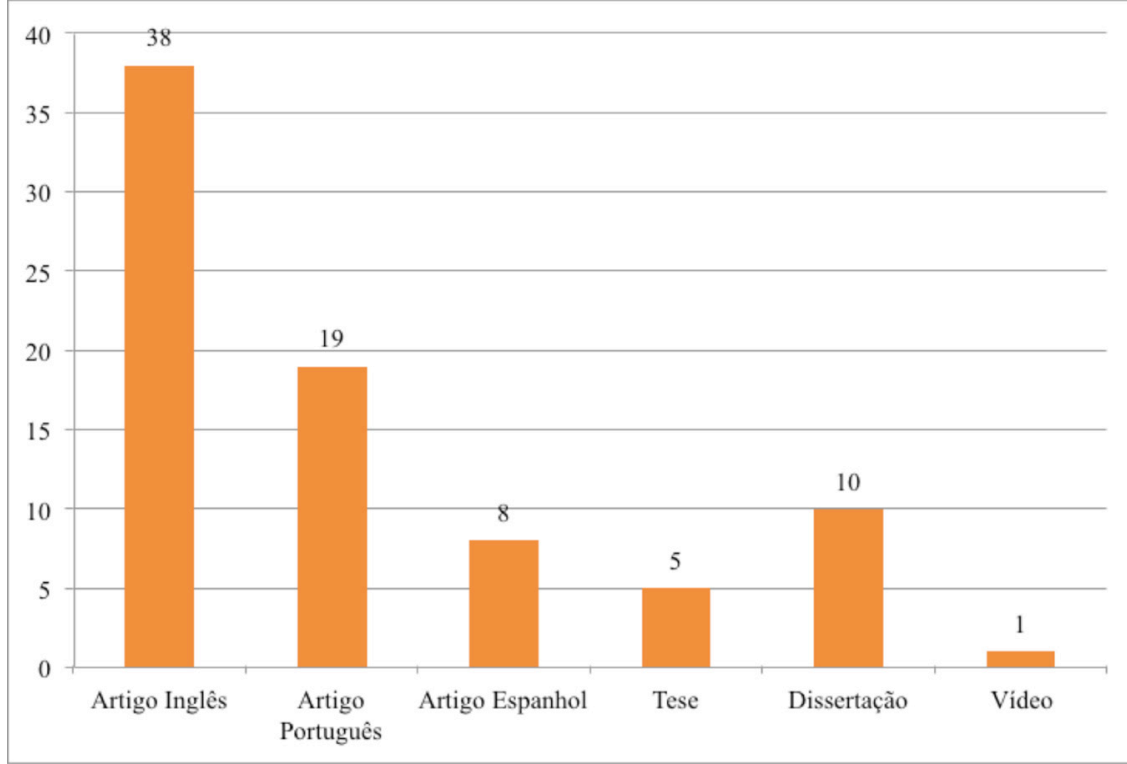

\section{Figura 2: Tipos de trabalhos selecionados}

Fonte: Elaborado pelas autoras, com base no levantamento bibliográfico.

Grande parte dos trabalhos é constituída por artigos científicos (a maioria deles em inglês), seguido de dissertaçóes, teses e um (1) vídeo cuja data de edição não pôde ser identificada. O número de publicações selecionadas por ano pode ser conferido no gráfico da Figura 3 a seguir, que mostra o incremento delas em 2009, 2010, 2012, 2013 e 2016.

Quando observados os países de vínculo dos autores dos trabalhos internacionais, observa-se maior incidência da Espanha (13), seguida dos Estados Unidos (8), Reino Unido (5), Turquia (5), China e África do Sul (3) e outros países com um ou dois vínculos, como Canadá, Portugal, Índia, Indonésia, Irlanda, Japão, Malásia, Mongólia, Nova Zelândia, Paquistão, Sérvia, Suécia, Suíça e Zimbabwe. Essa variedade de víncu- 


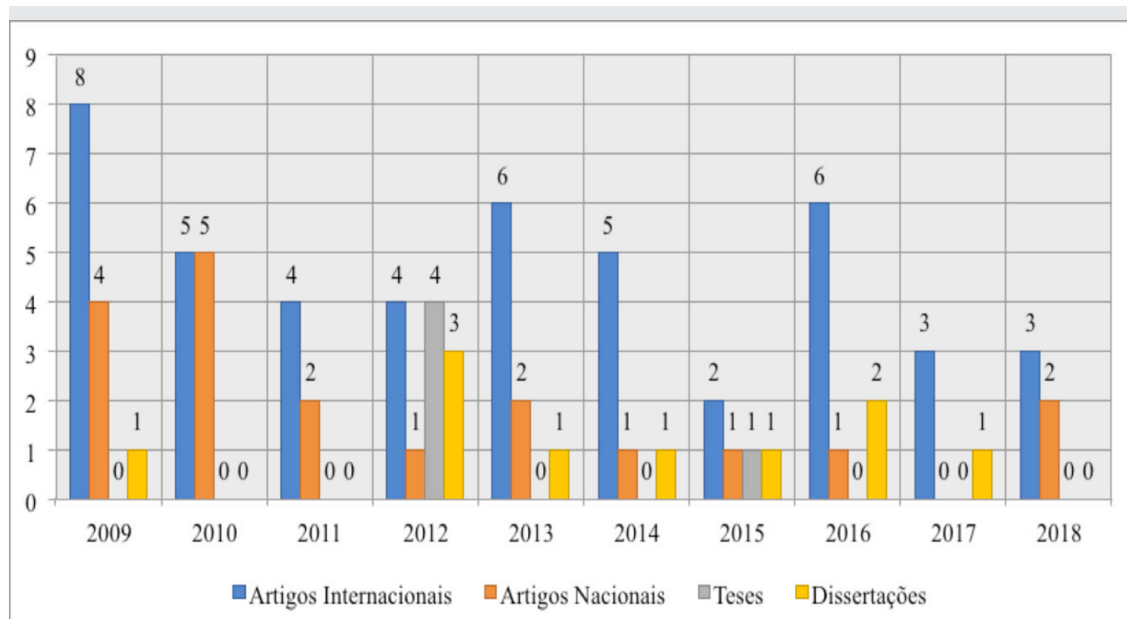

Figura 3: Quantidade de trabalhos acadêmicos selecionados por ano e tipo Fonte: Elaborado pelas autoras, com base no levantamento bibliográfico.

los institucionais demonstra que existe uma diversidade de estudiosos de variadas etnias e culturas pesquisando e estudando a $\mathrm{EaD}$ e suas relaçóes com a qualidade.

No Brasil, a maioria dos trabalhos é da região Sul (5), seguida do Nordeste (4), Sudeste (3) e Distrito Federal (2). As regiōes Centro-Oeste e Norte não tiveram nenhum trabalho selecionado.

O Quadro 1 a seguir traz o resumo das tendências dos estudos publicados nos repositórios pesquisados. Conforme o Quadro 1, a maioria dos textos cujos autores possuem vínculos com países de língua estrangeira considera a qualidade na $\mathrm{EaD}$ como instrumento de busca de aprimoramento, satisfação do estudante (tido muitas vezes como cliente), produtividade, em nome da competitividade, da performatividade e do individualismo, e em detrimento do processo formativo. Ou seja, poucos tratam a qualidade na $\mathrm{EaD}$ como justiça ou qualidade social, em que a pertinência e a relevância social são importantes, sem o rompimento da comunicação com a comunidade educativa (DIAS SOBRINHO, 2010). 


\begin{tabular}{|c|c|c|}
\hline Repositórios & Selecionados & Tendências Gerais \\
\hline ANPEd & 2 & $\begin{array}{l}\text { Os trabalhos encontrados tratam, em sua } \\
\text { maioria, da EaD de forma separada da temática } \\
\text { da qualidade. A tendência é tratar do conceito de } \\
\text { qualidade e da agenda para a EaD até } 2020 \text {. }\end{array}$ \\
\hline $\begin{array}{l}\text { BDTD e } \\
\text { Banco da } \\
\text { Capes }\end{array}$ & 13 & $\begin{array}{l}\text { Os trabalhos tratam da relação EaD e qualidade, } \\
\text { com perspectivas voltadas para a análise de } \\
\text { indicadores, instrumentos e atributos. }\end{array}$ \\
\hline Scielo & 9 & $\begin{array}{l}\text { Alguns textos tratam de } \mathrm{EaD} \text {, qualidade e } \\
\text { indicadores de forma isolada como contribuiçáo } \\
\text { para a construçáo de conceitos. Os textos que tratam } \\
\text { da relaçáo entre os dois objetos (EaD e qualidade) } \\
\text { possuem como foco a análise da qualidade e os } \\
\text { indicadores. }\end{array}$ \\
\hline $\begin{array}{l}\text { Portal } \\
\text { Periódicos } \\
\text { Capes }\end{array}$ & 15 & $\begin{array}{l}\text { Os textos tratam da relação qualidade e educação } \\
\text { a distância e a maioria deles possui foco na } \\
\text { mensuração, nos modelos, nos referenciais, nos } \\
\text { fatores e na avaliaçáo desses elementos. }\end{array}$ \\
\hline ERIC & 29 & $\begin{array}{l}\text { A maioria dos trabalhos considera a qualidade } \\
\text { relacionada à EaD como estratégia para a conquis- } \\
\text { ta de espaço, competição, serviço e benchmarking. } \\
\text { Poucos trabalhos a tratam como justiça social e } \\
\text { fator de desenvolvimento. }\end{array}$ \\
\hline RCAAP & 3 & $\begin{array}{l}\text { Os textos pensam a EaD relacionando a qualidade } \\
\text { com referenciais e indicadores. Relacionam ainda } \\
\text { qualidade e EaD. }\end{array}$ \\
\hline DDD UAB & 10 & $\begin{array}{l}\text { Os estudos relacionam a qualidade e a EaD em } \\
\text { uma perspectiva de avaliação e indicadores, porém, } \\
\text { a maioria dos textos apresenta tons de satisfação, } \\
\text { tais como competitividade e produtividade. }\end{array}$ \\
\hline
\end{tabular}

\section{Quadro 1: Quantidade de trabalhos selecionados por ano e tipo}

Fonte: Elaborado pelas autoras, com base no levantamento bibliográfico.

Nos próximos itens, serão analisados, nos textos selecionados e em outros documentos, o conceito e os usos de nomenclaturas relacionadas à oferta da educaçáo a distância e ao conceito de qualidade social na EaD. A partir desse conceito, serão estabelecidas a sua relação com as propostas de indicadores. 


\section{Educação a distância: entre nomenclaturas e regulamentaçóes}

Ao tratar de métodos de estudo da educação a distância, Saba (2015, p. 153) pontua que esse é um campo "[...]de natureza complexa, pois é composto de constructos oriundos de uma variedade de áreas acadêmicas, além de seus próprios conceitos, constructos e teorias de base". Sobre os conceitos fundamentais que envolvem as diversas nomenclaturas para se referir à educação a distância, cita o resultado de duas pesquisas: na primeira delas, os participantes foram convidados a definir e descrever os atributos dos termos educação a distância, e-learning e aprendizagem online. As respostas, porém, foram conflitantes, com grandes diferenças entre os significados, demonstrando que a falta de entendimento comum de conceitos fundamentais dificulta a classificação e a seleção dos resultados e a colaboração entre os estudiosos internacionalmente. $\mathrm{Na}$ segunda pesquisa foi feita uma análise exaustiva de e-learning, cuja conclusão apontou que o termo é confuso e que os autores pesquisados possuem visóes básicas equivocadas sobre como a EaD está definida.

Mill e Oliveira (2014), em pesquisa realizada em 83 teses publicadas no Brasil, constataram que, entre as que tinham a EaD como objeto, a maioria referia-se à modalidade utilizando a nomenclatura educação a distância, seguida pelas denominaçôes ensino a distância e educação online. Entre todas as teses, apenas três fizeram uso do termo e-learning. Pode-se dizer que, ao contrário do que ocorre em outros países, no Brasil a $\mathrm{EaD}$ não tem apresentado nomenclaturas diversas, inclusive as que são utilizadas nas regulamentações, a saber: educação a distância, método não presencial e semipresencial, e metodologia a distância.

Como já salientado anteriormente, a denominação educação a distância aparece pela primeira vez na Lei de Diretrizes e Bases da Educação Brasileira (LDB) no 9.394, de 20 de dezembro de 1996, que em seu Art. 80 destaca: "[...] o Poder Público incentivará o desenvolvimento e a veiculação de programas de ensino a distância, em todos os níveis e modalidades de ensino, e de educação continuada" (BRASIL, 1996, grifo nosso). Para regulamentar o referido artigo, o Governo Federal foi esta- 
belecendo uma série de normas para sua oferta. O Art. $1^{\circ}$ do Decreto $\mathrm{n}^{\circ}$ 9.057, de 25 de maio de 2017, que regulamenta a $\mathrm{EaD}$, a conceitua como

[...] a modalidade educacional na qual a mediação didáticopedagógica nos processos de ensino e aprendizagem ocorra com a utilização de meios e tecnologias de informação e comunicação, com pessoal qualificado, com políticas de acesso, com acompanhamento e avaliação compatíveis, entre outros, e desenvolva atividades educativas por estudantes e profissionais da educação que estejam em lugares e tempos diversos (BRASIL, 2017).

Apesar de haver discordâncias entre pesquisadores da área, a EaD é citada na maioria das regulamentaçôes como modalidade de ensino (tal como no Decreto no 9.057/2017, na Resolução CNE no 1/2016 e na Portaria MEC no 4.059/2004), e em poucos deles, como método ou metodologia (Portarias MEC no 2.253/2001 e no 1.428/2018). Todavia, a nomenclatura mais utilizada tem sido educação a distância.

Outra normatização do Art. 80 da LDB/1996 diz respeito à Portaria MEC no 1.428/2018 que rege a oferta de disciplinas a distância em cursos presenciais e que sofreu mudanças ao longo da trajetória da implantação da EaD no país, como se pode ver no Quadro 2 na próxima página.

Alonso (2010) e Lima e Assis (2018) defendem que as regulamentaçôes da educação superior em EaD têm sido utilizadas como estratégia para sua expansão, principalmente na esfera privada. Mas, conforme observado anteriormente, desde o Governo Temer (2016-2018) e agora no Governo Bolsonaro (2019), as regulamentaçôes implementadas têm demonstrado uma tendência para a ampliação do mercado educacional privado, e não como forma de democratizar o acesso e a inclusão com qualidade social. Trata-se, na verdade, de desregulamentaçóes.

O último Censo da Educação Superior (2018) corrobora essa assertiva, pois os dados levantados mostram que as matrículas na educação superior sofreram um aumento entre 2016 e 2017 na modalidade a distância (público e privada) e queda na modalidade presencial privada conforme Tabela 1 na página a seguir. 


\begin{tabular}{|c|c|c|c|c|}
\hline Portaria & $\begin{array}{l}\mathrm{n}^{\circ} 2.253 \text {, de } 18 \text { de } \\
\text { outubro de } 2001 \\
\text { REVOGADA }\end{array}$ & $\begin{array}{l}\text { no } 4.059 \text {, de } 10 \text { de } \\
\text { dezembro de } 2004 \\
\text { REVOGADA }\end{array}$ & $\begin{array}{l}\mathrm{n}^{\circ} 1.134 \text {, de } 10 \text { de } \\
\text { outubro de } 2016 \\
\text { REVOGADA }\end{array}$ & $\begin{array}{l}\text { no } 1.428 \text {, de } 28 \text { de } \\
\text { dezembro de } 2018 \\
\text { EM VIGOR }\end{array}$ \\
\hline $\begin{array}{l}\text { Termino- } \\
\text { logia }\end{array}$ & $\begin{array}{l}\text { Método não } \\
\text { presencial }\end{array}$ & $\begin{array}{l}\text { Modalidade } \\
\text { semipresencial }\end{array}$ & $\begin{array}{l}\text { Oferta na } \\
\text { modalidade a } \\
\text { distância }\end{array}$ & $\begin{array}{l}\text { Metodologia a } \\
\text { distância em cursos de } \\
\text { graduaçấo presencial }\end{array}$ \\
\hline Trechos & $\begin{array}{l}\text { Art. } 1^{\circ} \text { As } \\
\text { instituiçóes de } \\
\text { ensino superior } \\
\text { [...] poderáo intro- } \\
\text { duzir [...] a oferta } \\
\text { de disciplinas que, } \\
\text { em seu todo ou } \\
\text { em parte, utilizem } \\
\text { método náo } \\
\text { presencial. } \\
\text { § } 1 \text { oAs disciplinas } \\
\text { a que se refere o } \\
\text { caput [...] não } \\
\text { poderão exceder } \\
\text { a vinte por cento } \\
\text { do tempo previsto } \\
\text { para integralização } \\
\text { do respectivo } \\
\text { currículo. }\end{array}$ & $\begin{array}{l}\text { Art. } 1^{\circ} \text { As insti- } \\
\text { tuiçóes de ensino } \\
\text { superior poderão } \\
\text { introduzir [...] a } \\
\text { oferta de disciplinas } \\
\text { integrantes do } \\
\text { currículo que uti- } \\
\text { lizem modalidade } \\
\text { semi-presencial. } \\
\$ 2^{\circ} \text { Poderăo ser } \\
\text { ofertadas as disci- } \\
\text { plinas referidas no } \\
\text { caput, integral ou } \\
\text { parcialmente, desde } \\
\text { que esta oferta } \\
\text { não ultrapasse } 20 \\
\% \text { [...] da carga } \\
\text { horária total do } \\
\text { curso. }\end{array}$ & $\begin{array}{l}\text { Art. } 1^{\circ} \text { As } \\
\text { instituiçóes de } \\
\text { ensino superior } \\
\text { [...] poderão intro- } \\
\text { duzir [...] a oferta } \\
\text { de disciplinas na } \\
\text { modalidade a } \\
\text { distância. } \\
\$ 1^{\circ} \text { As disciplinas } \\
\text { referidas no } \\
\text { caput poderão ser } \\
\text { ofertadas, integral } \\
\text { ou parcialmente, } \\
\text { desde que esta } \\
\text { oferta não } \\
\text { ultrapasse } 20 \% \\
\text { [...] da carga } \\
\text { horária total do } \\
\text { curso. }\end{array}$ & $\begin{array}{l}\text { Art. } 1^{\circ} \text { Esta Portaria } \\
\text { dispóe sobre a oferta de } \\
\text { disciplinas com meto- } \\
\text { dologia a distância em } \\
\text { cursos de graduação } \\
\text { presencial ofertados } \\
\text { por Instituição de } \\
\text { Educação Superior. } \\
\text { Art. } 2^{\circ} \text { As IES [...] } \\
\text { poderấo introduzir a } \\
\text { oferta de disciplinas na } \\
\text { modalidade a distância } \\
{[\ldots] \text { até o limite de }} \\
20 \% \text { [...] da carga } \\
\text { horária total do curso. } \\
\text { Art. 3 O limite de } \\
20 \% \text { [...] poderá ser } \\
\text { ampliado para até } \\
40 \% \text {. }\end{array}$ \\
\hline
\end{tabular}

\section{Quadro 2: Portarias que tratam da oferta de disciplinas a distância em cursos presenciais no Brasil}

Fonte: Elaborado pelas autoras, com base nas portarias citadas (grifos nossos).

\section{Tabela 1: Matrículas na educação superior}

\begin{tabular}{c|c|c|c}
\hline \multicolumn{4}{c}{ Redes de Instituiçóes de Educação Superior Matrículas } \\
\hline Pública & Privada \\
\hline Presencial & $\mathrm{EaD}$ & Presencial & $\mathrm{EaD}$ \\
\hline \multicolumn{4}{|c}{$\mathbf{2 0 1 6}$} \\
\hline 1.867 .477 & 122.601 & 4.686 .806 & 1.371 .817 \\
\hline \multicolumn{4}{|c}{$\mathbf{2 0 1 7}$} \\
\hline 1.879 .784 & 165.572 & 4.649 .897 & 1.591 .410 \\
\hline \multicolumn{4}{c}{ Porcentagem entre 2016 e 2017 } \\
\hline $0,7 \%$ & $35 \%$ & $-0,8$ & $16 \%$ \\
\hline
\end{tabular}

Fonte: Elaborada pelas autoras, com base em dados do Inep (BRASIL, 2018). 
Mesmo considerando que as políticas públicas e as regulamentações possam contribuir para a expansão da $\mathrm{EaD}$ com vistas à ampliação de sua oferta com qualidade ou não, a preocupação do Brasil em regulamentar a modalidade tem alcançado boa repercussão. Comparativamente, alguns países ofertam cursos a distância apesar de não possuírem regulamentação específica para a modalidade, o que talvez justifique a gama de nomenclaturas utilizadas, tais como e-learning (SANGRÀ; VLACHOPOULOS; CABRERA, 2012), educação aberta (AIRES, 2016), educação híbrida (b-learning) (MONTEIRO; MOREIRA, 2013), educação móvel (m-learning) (SHARPLES et al., 2009).

De acordo com Carlsen et al. (2016), os estudantes dependem de programas de educação em tempo parcial e contínuo para cursar o ensino superior, e, por isso, são extremamente afetados por enquadramentos jurídicos desfavoráveis. Porém, conforme os autores, as políticas que orientam o desenvolvimento das provisóes de $\mathrm{EaD}$ no ensino superior são pouco frequentes, tanto que nos estudos de caso realizados por eles em cinco países, nenhum possuía política nacional de educação a distância implementada, conforme mostra o Quadro 3 a seguir.

\begin{tabular}{|l|l|}
\hline Finland & $\begin{array}{l}\text { No specific policy on distance education in higher education. No separate open or } \\
\text { distance teaching universities. }\end{array}$ \\
\hline Germany & No specific policy on distance education in higher education. \\
\hline Greece & $\begin{array}{l}\text { No specific policy on distance education in higher education. Mentioned in the } \\
\text { 'Education and Lifelong Learning' policy. }\end{array}$ \\
\hline Hungary & $\begin{array}{l}\text { No specific policy on distance education in higher education. On the master's level, } \\
\text { no distance education at all. No laws mentioning e-learning. }\end{array}$ \\
\hline UK & $\begin{array}{l}\text { No specific policy on distance education in higher education, but laws exist that } \\
\text { influence it indirectly e.g. Common quality assurance (QA) framework for higher } \\
\text { education }\end{array}$ \\
\hline
\end{tabular}

Quadro 3: Estrutura de políticas existentes ou aplicadas à EaD Fonte: Carlsen et al. (2016, p. 54). 
Embora muitas nomenclaturas estejam relacionadas à atividade a distância do processo de ensino-aprendizagem, destacam-se aqui aquelas em que se sobressaíram de alguma forma no levantamento bibliográfico, sejam trabalhadas em suas concepçôes, seja pela frequência com que apareceram. No Quadro 4 destacam-se os conceitos que emergiram das nomenclaturas e que são defendidos neste estudo.

\begin{tabular}{|c|c|}
\hline Nomenclatura & Conceito-chave \\
\hline $\begin{array}{l}\text { Educação a } \\
\text { Distância }\end{array}$ & $\begin{array}{l}\text { “Maneira/modo de organizar o processo educativo, contemplando sua principal } \\
\text { característica: professores e alunos năo estarem face a face durante todo o tempo } \\
\text { da formação" (ALONSO, 2010, p. 1326). } \\
\text { Com base no Relatório da Comissáo Assessora para a Educação Superior } \\
\text { a Distância, Nascimento e Carnielle (2007, p. 87) definem a EaD como: } \\
\text { "[...] atividade pedagógica que é caracterizada por um processo de ensino- } \\
\text { aprendizagem realizado com mediaçáo docente e a utilização de recursos didáticos } \\
\text { sistematicamente organizados, apresentados em diferentes suportes e tecnologias } \\
\text { de informaçãa e comunicação". }\end{array}$ \\
\hline E-learning & $\begin{array}{l}\text { "E-learning é uma abordagem de ensino e aprendizagem [...] que se baseia no } \\
\text { uso de meios e dispositivos eletrônicos como ferramentas para melhorar o acesso } \\
\text { à formaçáo, comunicação e interaçáo e que facilita a adoção de novas formas de } \\
\text { compreender e desenvolver a aprendizagem" (SANGRÄ; VLACHOPOULOS; } \\
\text { CABRERA, 2012, p. 152, tradução nossa). } \\
\text { "Aprendizagem Eletrônica (e-learning) é a educação baseada em métodos mo- } \\
\text { dernos de comunicação, incluindo o computador e suas redes, vários materiais } \\
\text { audiovisuais, mecanismos de busca, bibliotecas eletrônicas e sites, sejam eles } \\
\text { realizados em sala de aula ou a distância" (AJMERA; DHARAMDASANI, } \\
\text { 2014, p. 90, traduçáo nossa). }\end{array}$ \\
\hline $\begin{array}{l}\text { Educação } \\
\text { Aberta }\end{array}$ & $\begin{array}{l}\text { Apoiada em Peters (2008), Aires (2016, p. 258) define: "A Educaçáo Aberta é } \\
\text { um dos movimentos educativos mais importantes do séc. XXI). [...] Tendo por } \\
\text { base, entre outros, a convergência e evoluçáo dos recursos educativos abertos, do } \\
\text { software livre, do livre acesso, dos MOOCs, da ciência aberta e de um conjunto } \\
\text { de mudanças sociais e econômicas, a matriz deste movimento ultrapassa o mero } \\
\text { acesso a conteúdos e recursos e associa-se a uma nova filosofia educativa". }\end{array}$ \\
\hline $\begin{array}{l}\text { Educação } \\
\text { híbrida } \\
\text { (blended } \\
\text { learning) }\end{array}$ & $\begin{array}{l}\text { "Mais do que integrar momentos presenciais e não presenciais, entendemos [...] } \\
\text { que o blended learning é uma estratégia dinâmica que envolve diferentes recursos } \\
\text { tecnológicos, diferentes abordagens pedagógicas e diferentes espaços (formais e } \\
\text { informais)" (MONTEIRO; MOREIRA, 2013, p. 33). }\end{array}$ \\
\hline $\begin{array}{l}\text { Educação } \\
\text { Móvel } \\
\text { (mobile } \\
\text { learning) }\end{array}$ & $\begin{array}{l}\text { "Os processos (pessoais e públicos) de vir a conhecer através da exploração e } \\
\text { conversaçáo em vários contextos, entre pessoas e tecnologias interativas" (SHAR- } \\
\text { PLES et al., 2009, p. 5, tradução nossa). Para desenvolver na educação formal é } \\
\text { necessário que se tenha: acesso à tecnologia, tecnologia móvel, conectividade com } \\
\text { compartilhamentos e integração de projetos móveis no currículo (p. 7). }\end{array}$ \\
\hline
\end{tabular}

Quadro 4: Nomenclaturas de oferta de cursos/formação a distância e conceitos Fonte: Elaborada pelas autoras, com base nos autores citados no quadro. 
Mesmo tendo clareza sobre a diversidade de nomenclaturas e termos que expressam a oferta da formação a distância, acolhe-se nesta pesquisa a de educação a distância por figurar na maioria dos estudos nacionais selecionados no levantamento e por ser a terminologia utilizada nas regulamentações no Brasil. Além dos conceitos de Alonso (2010) e Nascimento e Carnielle (2007), mostrados no Quadro 4, considera-se a $\mathrm{EaD}$ como

[...] uma prática social educativa-dialógica de um trabalho coletivo, de autoria e colaborativo, articulada para o desenvolvimento de uma arquitetura pedagógica e de gestáo, integrada ao uso significativo das tecnologias de informação e comunicação, voltada para a formação crítica, autônoma e emancipadora (LIMA, 2014, p. 60).

No próximo item serão analisados os conceitos de qualidade e de qualidade na $\mathrm{EaD}$, bem como suas repercussóes como indicadores de qualidade.

\section{Conceitos de qualidade e qualidade na EaD: lente teórica e análise por indicadores}

Discutir a qualidade da oferta de cursos de educação superior e a distância torna-se tarefa emergente, inclusive, pela forma como vem sendo desenvolvida no Brasil (privatista e expansionista) e no mundo. De acordo com Latchem (2015), a comunidade universitária mostra descrédito com a qualidade dos cursos, pelo fato de serem frequentemente oferecidos com intençóes comerciais ou econômicas. O autor destaca que existem, dentre outras, questóes relativas à oferta da $\mathrm{EaD}$ em nível superior e a distância que ainda não foram respondidas: que mecanismos sistemáticos e "Quality Assurance (QA)" são necessários para demonstrar qualidade dos cursos ofertados? Como culturas diferentes interpretam e medem a qualidade da EaD?

Enfim, para tratar de qualidade e de qualidade na educação superior e a distância, é preciso esclarecer quais os conceitos que se defende neste es- 
tudo, visto que os trabalhos selecionados para a pesquisa apresentam duas distintas visôes: aqueles cujos autores têm uma perspectiva economicista da educação, que é considerada como um processo produtivo, e outros que defendem um processo global, em que toda a comunidade participe do processo, que envolve a qualidade social com equidade.

Defende-se aqui uma proposta de qualidade na educação que tenha como base o segundo viés, ou seja, de qualidade social. Tal opçáo coaduna com o que afirma Dias Sobrinho (2010), ou seja, que a educação é um bem público, direito social e dever do Estado, e sua qualidade está imbricada na dimensão social e pública. Dourado e Oliveira (2009) veem a qualidade na educação em uma perspectiva polissêmica, cuja concepção de mundo, de sociedade e de educação evidenciam os elementos para qualificar os atributos desejáveis de um processo educativo de qualidade social, considerando os diferentes espaços, atores e processos formativos, bem como a trajetória histórico-cultural do projeto de nação referido. Por sua vez, Morosini (2009) considera a qualidade como um construto imbricado no contexto das sociedades, e cuja concepção deve ser pensada e implementada com equidade.

Considerando essas bases, conclui-se ser fundamental estabelecer dimensôes e indicadores de qualidade a serem examinados como referências analíticas e políticas, e que sirvam como mecanismos de controle social, implementação, acompanhamento e avaliação de políticas, programas e açóes para construir uma educação superior e a distância de qualidade socialmente referendada (DOURADO; OLIVEIRA, 2009). Assim, desenvolve-se a partir daqui o conceito de qualidade social com vistas à equidade na $\mathrm{EaD}$, para construir, com base nos autores selecionados, uma proposta inicial de dimensóes e indicadores em nível meso e micro e que possam contribuir para a autoavaliação das instituiçôes de educação superior no Brasil.

Denomina-se proposta inicial porque, com base na qualidade social, acredita-se que ela deva ser posteriormente validada empiricamente em cada instituição, com a participação de professores, estudantes, gestores, pesquisadores e técnicos, além de membros da comunidade externa. Não se tem como foco a análise de desempenho, e sim a definição de elementos que revelem uma direção de forma qualitativa, mostrando determinada situação para, assim, contribuir para novas açóes. 
Vejamos agora, a partir dos trabalhos selecionados, o que podemos entender por qualidade na $\mathrm{EaD}$ superior e quais poderiam ser suas dimensôes e indicadores de análise em nível meso e micro institucional. De acordo com o International Council for Open and Distance Education (ICDE, 2015), como o conceito de qualidade é complexo e com uma variedade de partes interessadas, a qualidade do e-learning pode ser revista a partir de três níveis: macro, que engloba as dimensóes gerais nacionais/globais; meso, que se refere às questóes institucionais; e micro, que diz respeito ao curso como tal. Portanto, a decisão de aprimorar ou revisar a qualidade em e-learning na seleçáo do ensino superior que servirá de modelo de qualidade será influenciada pelo nível e pelo objetivo da revisão.

Consideram-se as dimensôes como os múltiplos aspectos macros baseados na literatura que são relevantes em um determinado objeto e os indicadores, como elementos que geram informaçóes do estado real do objeto, favorecendo a realização de proposições posteriores. Mais especificamente, indicadores são os elementos necessários para avaliar se os objetivos educacionais da formação a distância estão sendo desenvolvidos. Cabe salientar que se considera que esse processo deve acompanhar o fenômeno universitário como um todo, ou seja, em sua complexidade, em seu movimento, em sua articulação e interdependência, e isso não requer milhares de dados fragmentados, e sim informaçóes que os sistematizem, relacionem e organizem e os aliviem de maneira relevante (RAMA, 2015).

Apesar de se considerar aqui a construção qualidade na $\mathrm{EaD}$ com base em uma perspectiva social, não se pode negar a influência internacional que o Brasil tem sofrido para que seja vista sob a perspectiva economicista. Vários documentos produzidos por organismos multilaterais e da Uniāo Europeia, principalmente a Associação Europeia para a Garantia da Qualidade no Ensino Superior (ENQA) e o Conselho Internacional para a Educação Aberta e a Distância (ICDE), vêm defendendo que o e-learning é um fator de qualidade da educação superior, porém, na prática, o utilizam em uma perspectiva de competitividade.

Para a oferta da educação superior com qualidade mediante o uso de e-learning, algumas características estão incorporadas a ela nos documentos produzidos pelas entidades citadas anteriormente: associar seu 
uso à educação presencial; ser transfronteiriça ou transnacional (com previsão de garantia de mobilidade e internacionalização); proporcionar acesso público às tecnologias de informação e comunicação (contribui para o desenvolvimento dos cursos e ajuda a ampliar o fosso digital e econômico do país); desenvolver sistemas de avaliação e acreditação (RUBIN, 2010).

$\mathrm{Na}$ União Europeia, o ensino aberto e a distância começou a aparecer em documentos de políticas e programas de financiamento em 1988. As políticas de $\mathrm{EaD}$ são declaradas como instrumentos para melhorar o papel sociopolítico que a educação e a formação desempenham na busca de sucesso econômico e competitividade. Em continuidade a essa lógica, novos programas vão sendo lançados (eEurope/1999; Processo de Bolonha/1999; Comunicado de Praga/2001; Comunicado de Bucareste/2012; Comissáo Europeia de Abertura da Educação/2013; The EU's Europe 2020 Strategy/2014), tendo sempre o e-learning, o desenvolvimento das tecnologias da informação e comunicação e o acesso a elas como foco na área da educação (CARLSEN et al., 2016).

Quando o tema é a qualidade da EaD, a maioria dos trabalhos selecionados neste estudo a relaciona com a oferta de cursos que fazem uso das tecnologias de informação e comunicação (TIC) ou tecnologias digitais de informação e comunicação (TDIC). Defendem ainda que a educação tradicional e presencial seja combinada com a educação a distância; que possua infraestrutura física e de pessoal completa para a $\mathrm{EaD}$; que disponha de uma rede nacional e internacional para desenvolver açóes colaborativas com mobilidade virtual; e, por fim, que o modelo pedagógico priorize a interação próxima entre alunos e professores (MALIK, 2015).

Vlachopoulos (2016) afirma que atualmente é a Associação Europeia de Garantia de Qualidade (ENQA) que coordena e formula as Normas e Diretrizes de QA no Espaço Europeu de Educação Superior. Conforme o autor, a entidade apresenta como postulado que a EaD não seja avaliada separadamente, e sim como parte integrante da educaçáo superior. Afirma ainda que, conforme constatado em outras pesquisas, uma das principais críticas aos cursos a distância continua sendo sua baixa qualidade, enquanto a educação presencial tem sido vista como de alta qualidade. 
$\mathrm{O}$ acompanhamento da qualidade da $\mathrm{EaD}$, ainda de acordo com Vlachopoulos (2016), tem se desenvolvido de forma fragmentada e com base em nove dimensôes: estrutura organizacional e administrativa da instituição para atender aos requisitos exigidos; infraestrutura tecnológica; apoio aos estudantes; planejamento e desenvolvimento educacional; educadores e apoio/formaçáo educacional; protocolos de acesso aos serviços eletrônicos; prosperidade financeira; requisitos legais e regulamentares; e avaliação do programa. Porém, para além de analisar a qualidade da $\mathrm{EaD}$ com base no conteúdo ofertado, na pedagogia utilizada e nos resultados de aprendizagem, é necessário ter certa flexibilidade, uma vez que cada instituição possui uma realidade. Além disso, deve-se considerar o processo, que é composto por uma combinação de fatores que contribuem para a vivência educacional e as aprendizagens, ou seja, as necessidades dos educandos, o uso de dados para tomada de decisão, a análise administrativa e os resultados das aprendizagens dos estudantes. Vale ressaltar que a comunicação, a interação e a aprendizagem são os elementos que os estudantes destacam como constituintes da qualidade.

Singh e Mishra (2016), com o mesmo postulado de Malik (2015), defendem que um dos elementos importantes para a qualidade está relacionado com a prática da interação e da comunicaçáo como meios para eliminar a distância entre professor e aluno. Essas açôes teriam como base: as abordagens de ensino e aprendizagem desenvolvidas entre os indivíduos e grupos do curso; a utilização de rotas de estudo para os estudantes; e o estabelecimento de ambiente e linguagem amigáveis para associações pessoais.

Considerando o que já foi estabelecido para a $\mathrm{EaD}$ no ensino superior no Brasil e as análises dos autores citados neste e em demais estudos utilizados na pesquisa, tais como Versuti (2008), Gómez (2015) e Morosini et al. (2016), propóem-se dimensões e indicadores em nível meso e micro (proposto também por nós na Figura 4 a seguir) para que possam ser utilizados no processo de elaboração da autoavaliaçáo e do acompanhamento da qualidade do uso da formação a distância nas instituições de educação superior (IES). A maioria dos autores internacionais defende a provisão de uma comissão institucional para assegurar a qualidade.

A Lei no 10.861, de 14 de abril de 2004, que institui o Sistema Nacional de Avaliação da Educação Superior (Sinaes), prevê como meca- 
nismos de aferição a avaliação institucional (in loco), a avaliação dos cursos de graduação (in loco) e o Exame Nacional de Desempenho de Estudantes - Enade (BRASIL, 2004). A avaliação institucional divide-se em autoavaliação, realizada pela IES, e avaliação externa, a cargo de comissóes designadas pelo Inep. Para o desenvolvimento da avaliação interna, cada IES compõe uma Comissão Própria de Avaliação (CPA). Assim, no Brasil, essa CPA poderia também ser responsável pelo acompanhamento dos resultados das avaliaçóes, atuando como comissão que assegure a qualidade na perspectiva social defendida pelas autoras deste artigo.

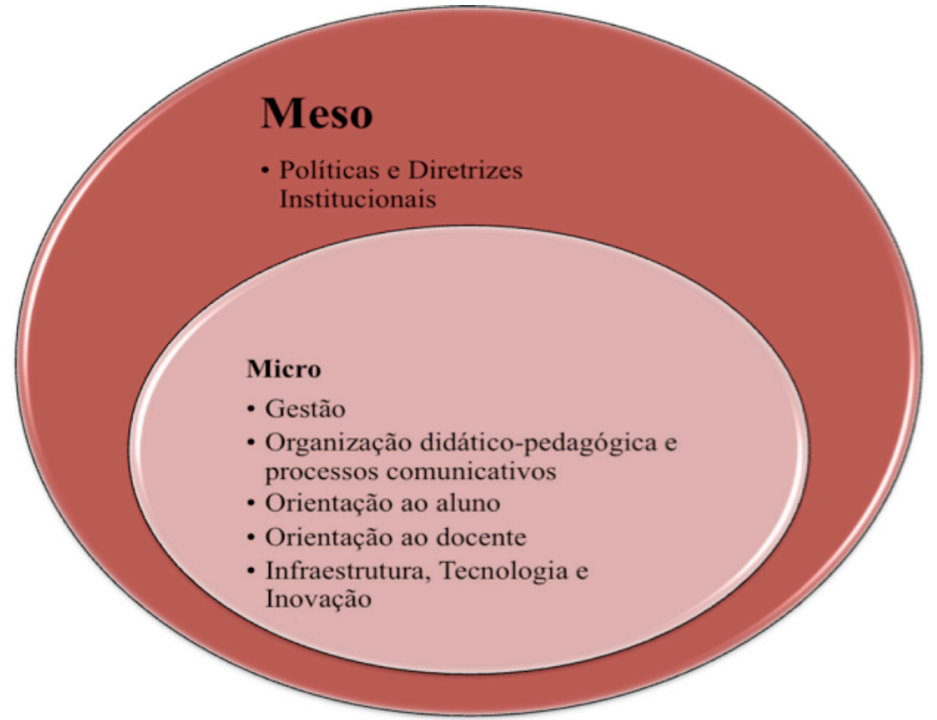

Figura 4: Níveis e dimensóes de análise de qualidade na oferta de formação a distância nas IES

Fonte: Elaborado pelas autoras, com base nos autores citados neste estudo.

Para o nível meso, tem-se a dimensão intitulada "Políticas e Diretrizes Institucionais". Os indicadores vinculados a essa dimensão podem ser aferidos de forma quantitativa ou qualitativa, conforme o Quadro 5.

Ao considerar o nível micro, chega-se às dimensões constantes do Quadro 6 a seguir, também construídas com base nos autores já citados neste estudo. 


\begin{tabular}{|c|c|c|}
\hline \multicolumn{3}{|r|}{ Nível Meso } \\
\hline \multicolumn{3}{|c|}{ Dimensão: Políticas e Diretrizes Institucionais } \\
\hline \multicolumn{3}{|r|}{ Indicadores } \\
\hline \multirow{2}{*}{$\begin{array}{l}\text { Documentos } \\
\text { Institucionais }\end{array}$} & $\begin{array}{l}\text { Articulação e Presença da } \\
\text { EaD }\end{array}$ & $\begin{array}{l}\text { Plano de Desenvolvimento Institucional (PDI) } \\
\text { Projeto Pedagógico Institucional (PPI) } \\
\text { Estatuto } \\
\text { Regimento } \\
\text { Autoavaliação institucional } \\
\text { Representação nos organismos superiores das instituiçôes }\end{array}$ \\
\hline & $\begin{array}{l}\text { Definição, uso e clareza } \\
\text { dos objetivos da EaD }\end{array}$ & $\begin{array}{l}\text { Plano de Desenvolvimento Institucional (PDI) } \\
\text { Projeto Pedagógico Institucional (PPI) } \\
\text { Estatuto } \\
\text { Regimento } \\
\text { Autoavaliação institucional } \\
\text { Uso da EaD em cursos presenciais } \\
\text { Representaçáo nos organismos superiores das instituiçóes }\end{array}$ \\
\hline \multirow{8}{*}{$\begin{array}{l}\text { Gestão } \\
\text { Específica da } \\
\text { EaD }\end{array}$} & $\begin{array}{c}\text { Cargos de Gestão } \\
\text { específicos para atuar na } \\
\text { EaD }\end{array}$ & $\begin{array}{l}\text { Cargos de gestão para EaD dentro das Reitorias ou } \\
\text { Diretorias }\end{array}$ \\
\hline & $\begin{array}{l}\text { Estrutura para Desenvolvi- } \\
\text { mento da EaD }\end{array}$ & $\begin{array}{l}\text { Unidade, Secretaria, Centro, coordenação ou órgão de } \\
\text { EaD } \\
\text { Equipe multidisciplinar }\end{array}$ \\
\hline & $\begin{array}{l}\text { Ênfase na estrutura orga- } \\
\text { nizacional que incentiva } \\
\text { processos democráticos, de } \\
\text { diálogo e trabalho coletivo } \\
\text { nas tomadas de decisáo }\end{array}$ & $\begin{array}{l}\text { Comissóes de trabalho } \\
\text { Reuniōes colegiadas } \\
\text { Processos de tomada de decisão de forma colaborativa e } \\
\text { colegiada }\end{array}$ \\
\hline & $\begin{array}{l}\text { Sistemas de formação } \\
\text { inicial e continuada para } \\
\text { EaD }\end{array}$ & $\begin{array}{l}\text { Oferta de Cursos de formação docente } \\
\text { Material de orientação de uso da EaD em cursos } \\
\text { presenciais }\end{array}$ \\
\hline & $\begin{array}{l}\text { Estabilidade da oferta dos } \\
\text { cursos }\end{array}$ & Continuidade dos cursos \\
\hline & $\begin{array}{l}\text { Política de registro e } \\
\text { acompanhamento discente } \\
\text { EaD }\end{array}$ & $\begin{array}{l}\text { Admissão, registro, reconhecimento e certificação } \\
\text { acadêmica dentro do registro global da IES } \\
\text { Regulamentos predefinidos com a inclusão de alunos EaD } \\
\text { Acompanhamento de egressos }\end{array}$ \\
\hline & $\begin{array}{l}\text { Política de transitabilidade } \\
\text { permanente do discente } \\
\text { EaD }\end{array}$ & $\begin{array}{l}\text { Mobilidade estudantil entre cursos e instituiçóes } \\
\text { Mobilidade dentro do próprio curso } \\
\text { Presença de alunos e professores estrangeiros }\end{array}$ \\
\hline & $\begin{array}{l}\text { Relaçóes com outras } \\
\text { instituiçóes de EaD }\end{array}$ & $\begin{array}{l}\text { Pesquisa } \\
\text { Mobilidade estudantil } \\
\text { Cooperação interinstitucional }\end{array}$ \\
\hline \multirow{2}{*}{$\begin{array}{l}\text { Mecanismos } \\
\text { de Acompa- } \\
\text { nhamento }\end{array}$} & $\begin{array}{l}\text { Avaliação de cursos e } \\
\text { projetos a distância }\end{array}$ & $\begin{array}{l}\text { Autoavaliação institucional } \\
\text { Membro pesquisador EaD na CPA }\end{array}$ \\
\hline & Garantia de Qualidade & $\begin{array}{l}\text { Pesquisa } \\
\text { Estatísticas } \\
\text { História, tendências e provisôes }\end{array}$ \\
\hline $\begin{array}{l}\text { Efetividade } \\
\quad \text { social }\end{array}$ & $\begin{array}{l}\text { Financiamento global da } \\
\text { IES } \\
\text { Custos baseados na } \\
\text { pertinência social }\end{array}$ & $\begin{array}{l}\text { Relação custo } \mathrm{x} \text { aluno inicial e final } \\
\text { Autonomia das decisões e processos financeiros }\end{array}$ \\
\hline
\end{tabular}

\section{Quadro 5: Dimensão das políticas e diretrizes institucionais em nível meso}

Fonte: Elaborado pelas autoras. 


\section{Quadro 6: Dimensão das políticas e diretrizes institucionais em nível micro}

Fonte: Elaborado pelas autoras.

(Continua...)

Criaçấo coletiva de documentos institucionais de regulamentação da oferta da $\mathrm{EaD}$ (projetos, regimentos e regulamentos)

Coordenação do trabalho da equipe multidisciplinar de $\mathrm{EaD}$

Planejamento, coordenação e desenvolvimento de cursos, projetos e açōes que envolvam a EaD, com critérios e instrumentos de coordenação e acompanhamento de cada etapa Organizaçấo do banco de dados do sistema: registro e acompanhamento acadêmico, cadastro de professores, designers, programadores, tutores, coordenadores e outros

Promoçẫo de logística de suporte aos processos de tutoria presencial e a distância, produção e distribuição de material

Construçáo coletiva de documentos para a oferta de Cursos em

Desenvolvimento e disponibilidade de cronograma, informaçôes e açóes de cursos em $\mathrm{EaD}$

Construção de mecanismos de acompanhamento do desenvolvimento dos cursos - da atuaçáo docente, tutoria e atendimento ao Construçáo de mecanismos de acompanhamento do desenvolvimento do processo ensino-aprendizagem dos cursos: estatística dos resultados de aprendizagem.

Material de orientação e regulamentaçáo do uso da $\mathrm{EaD}$ em cursos presenciais

Consonância com o Projeto Pedagógico de Curso, número de vagas e investimentos no curso Aquisição de materiais e equipamentos

Logística de entrega de materiais e encontros presenciais Relação financiamento $\mathrm{x}$ custo $\mathrm{x}$ evasão

Utilização de recursos tecnológicos para interação no curso Feedback aos trabalhos e questōes como orientaçăo e tempo útil

Decisóes partilhadas para o desenvolvimento do processo pedagógico

Orientaçôes detalhadas sobre o percurso do processo de ensino e aprendizagem para o aluno (rotas de estudo).

Materiais orientadores sobre o curso.

Materiais do curso compatíveis com o Projeto Pedagógico e o

Equilíbrio entre as atividades individuais e colaborativas Materiais orientadores sobre o uso da $\mathrm{EaD}$ em cursos presenciais

Definição de um ambiente, plataforma ou espaço virtual para os processos de interação e mediação pedagógica

Uso de variadas ferramentas digitais de informaçáo e comunicação: chat, Fórum, mensagem, WhatsApp, redes sociais, Código Bidimensional (QR Code), YouTube, vídeo e web conferência, gameficação, comunidades de aprendizagem, uso de dispositivos móveis, dentre outros

Uso de tecnologias digitais de informação e comunicação

Uso de espaços presenciais e a distância

Uso de diversas abordagens metodológicas Uso de espaços formais e não formais 


\begin{tabular}{|c|c|c|}
\hline & $\begin{array}{l}\text { Currículos } \\
\text { inovadores }\end{array}$ & $\begin{array}{c}\text { Explicitação da teoria e prática de forma articulada } \\
\text { Previsão de práticas pedagógicas } \\
\text { Flexibilidade de tempo e espaço }\end{array}$ \\
\hline & $\begin{array}{l}\text { Avaliação } \\
\text { processual e final }\end{array}$ & $\begin{array}{l}\text { Avaliação compreensiva, embasada nos objetivos, trabalho } \\
\text { acadêmico e práticas pedagógicas } \\
\text { Uso de diferentes processos de avaliação durante o curso } \\
\text { Monitoramento dos caminhos trilhados individualmente e de } \\
\text { cada grupo de estudantes }\end{array}$ \\
\hline \multirow[t]{3}{*}{$\begin{array}{l}\text { Orientaçáo e } \\
\text { acompanha- } \\
\text { mento ao aluno }\end{array}$} & Formação em EaD & $\begin{array}{c}\text { Orientação e domínio do uso dos recursos tecnológicos } \\
\text { utilizados }\end{array}$ \\
\hline & $\begin{array}{l}\text { Acompanhamento, } \\
\text { apoio e perma- } \\
\text { nência }\end{array}$ & $\begin{array}{c}\text { Relação matriculados e concluintes por turma } \\
\text { Auxílio alimentação e transporte, quando for o caso } \\
\text { Programas de inserção acadêmica: iniciaçấo científica, monitoria } \\
\text { e projetos de extensão } \\
\text { Ofertas de estudos ou cursos compensatórios, inclusive na área } \\
\text { da tecnologia }\end{array}$ \\
\hline & Internacionalização & Mobilidade virtual em atividades fora do país \\
\hline \multirow[t]{3}{*}{$\begin{array}{l}\text { Orientaçáo e } \\
\text { acompanha- } \\
\text { mento para o } \\
\quad \text { docente }\end{array}$} & $\begin{array}{l}\text { Titulação e forma- } \\
\text { ção condizente e } \\
\text { em EaD }\end{array}$ & $\begin{array}{c}\text { Conhecimento e formação específica das possibilidades em EaD } \\
\text { Ter orientação/formaçâo e domínio do uso dos recursos } \\
\text { tecnológicos utilizados }\end{array}$ \\
\hline & $\begin{array}{l}\text { Apoio ao } \\
\text { desenvolvimento } \\
\text { dos cursos }\end{array}$ & $\begin{array}{c}\text { Formação específica sobre o curso } \\
\text { Apoio da gestáo pedagógica, técnica e tecnológica para o } \\
\text { desenvolvimento do curso } \\
\text { Apoio nos cursos presenciais com uso da EaD }\end{array}$ \\
\hline & $\begin{array}{l}\text { Monitoramento } \\
\text { constante do } \\
\text { desenvolvimento } \\
\text { das turmas e dos } \\
\quad \text { alunos }\end{array}$ & $\begin{array}{c}\text { Mecanismos rotineiros e implementados para acompanhamento } \\
\text { do desenvolvimento pedagógico, de acesso e uso das ferramentas } \\
\text { tecnológicas no curso pelos estudantes }\end{array}$ \\
\hline \multirow[t]{4}{*}{$\begin{array}{l}\text { Infraestrutu- } \\
\text { ra, tecnologia } \\
\text { e inovaçäo }\end{array}$} & $\begin{array}{l}\text { Desenvolvimento } \\
\text { e sustentabilidade } \\
\text { da infraestrutura } \\
\text { tecnológica }\end{array}$ & $\begin{array}{l}\text { Plataforma/Ambiente/Espaço Digital } \\
\text { Biblioteca Virtual com textos e materiais previstos nos cursos } \\
\text { Sistema centralizado com apoio, desenvolvimento, manutenção e } \\
\text { atendimento digital }\end{array}$ \\
\hline & $\begin{array}{l}\text { Disponibilidade } \\
\text { de informaçóes e } \\
\text { suporte }\end{array}$ & $\begin{array}{l}\text { Informação e formação aos estudantes e demais profissionais } \\
\text { sobre como lidar com as bases de dados, empréstimos/acessos } \\
\text { interbibliotecas, como salvaguardar materiais de estudo } \\
\text { Alunos e professores possuem acesso à assistência técnica, sessóes } \\
\text { práticas antes do início do curso e acesso satisfatório à equipe técnica } \\
\text { Serviço de helpdesk ágil aos estudantes e demais profissionais }\end{array}$ \\
\hline & $\begin{array}{l}\text { Acesso e } \\
\text { desenvolvimento } \\
\text { pedagógico em } \\
\text { diversos recursos } \\
\text { tecnológicos }\end{array}$ & $\begin{array}{c}\text { Chat, Fórum, mensagem, WhatsApp, redes sociais, Código } \\
\text { Bidimensional (QR Code), YouTube, vídeo e web conferência, } \\
\text { gameficação, dentre outros }\end{array}$ \\
\hline & $\begin{array}{l}\text { Equidade e justiça } \\
\text { digital }\end{array}$ & $\begin{array}{c}\text { Formação técnica para estudantes, docentes, técnicos, gestores } \\
\text { e demais profissionais para o uso das tecnologias da informação } \\
\text { e comunicação e para as tecnologias digitais de informaçáo e } \\
\text { comunicaçáo. } \\
\text { Promoção de comunidades interativas a partir dos interesses e } \\
\text { necessidades dos atores }\end{array}$ \\
\hline \multicolumn{3}{|c|}{$\begin{array}{l}\text { (continuação) Quadro 6: Dimensão das políticas e diretrizes institucionais } \\
\text { em nível micro } \\
\text { Fonte: Elaborado pelas autoras. }\end{array}$} \\
\hline
\end{tabular}




\section{Conclusão}

Diante do exposto e considerando a importância de se ressignificar as discussôes sobre qualidade e, a partir desta, da qualidade em EaD, há de se pensar o movimento que se estabelece em uma reflexão teórica que configure determinada proposição. É esta a tentativa que se fez no trabalho em tela. O movimento aqui mencionado tem a ver, portanto, com olhares e lugares implicados em uma definição que não é descolada, em hipótese nenhuma, de um contexto referenciado teoricamente e que precede a proposição de todo e qualquer indicador, no caso, de qualidade, configurando o entendimento que o 'localiza' em uma determinada perspectiva, e não em outra.

No presente trabalho a perspectiva da qualidade social precede a toda e qualquer alusão ao indicador, portanto, a díade qualidade social versus indicador é tomada aqui como necessária, talvez não suficiente para se pensar a consolidação da oferta com qualidade da EaD, na expectativa de uma democratizaçáo que avance na e para a construção da cidadania, mediante sua oferta gratuita e pública. Afirmar tais valores como princípios que intencionam uma oferta educativa/formativa é fundamental para que, a partir daí, se proponham indicadores. Trabalhar com indicadores requer uma certa "profissão de fé" no sentido de se incluir/pensar os valores e princípios antes mencionados, de modo que se faça a adesão a um ideal que sustente a qualidade da educação e, por consequência, da qualidade em EaD.

Considera-se que o movimento externado no trabalho seja o início de um debate que constitua significados outros que possam ir além de uma visão mais implicada com desígnios mercadológicos, tais como os encontrados em parte da revisão de literatura que deu base às reflexôes, ou ainda que, por conta das especificidades da $\mathrm{EaD}$, se tenha uma visão apartada dos cotidianos institucionais, propondo indicadores que salientem mais essa condição do que a do processo educativo.

O grande desafio, ao que parece (e uma das aprendizagens que se teve neste trabalho), será o de pensar/refletir sobre os trânsitos e movimentos teóricos implicados entre intençôes, níveis, dimensóes e indicadores que corroborem, de fato, uma qualidade que contribua para a superação das desigualdades sociais e históricas como as que existem no Brasil. 


\section{Nota dos autores}

1 Esta pesquisa foi realizada com apoio da Capes/Fapeg e CNPq.

\section{Referências}

AIRES, L. E-learning, Educação Online e Educação Aberta: Contributos para uma reflexão teórica. Revista Iberoamericana de educación a distancia - RIED, Madrid/ Espanha, v. 19, n. 1, p. 253-269, 2016. Disponível em: http://revistas.uned.es/index. php/ried/article/view/14356/. Acesso em: 10 fev. 2019.

AJMERA, R.; DHARAMDASANI, D. K. E-learning Quality Criteria and Aspects. International Journal os Computer Trends and Technology, Thennur/India, v. 12, n. 2, p. 90-93, 2014. Disponível em: https://arxiv.org/pdf/1406.7744.pdf/. Acesso em: 13 jan. 2019.

ALONSO, K. M. A expansão do ensino superior no Brasil e a EaD: Dinâmicas e Lugares. Educ. Soc., Campinas, SP, v. 31, n. 113, p. 1319-1335, 2010. Disponível em: http://www.scielo.br/pdf/es/v31n113/14.pdf/. Acesso em: 12 jan. 2019.

BERTOLIN, J. C. G.; MARCHI, A. C. B. de. Instrumentos para avaliar disciplinas da modalidade semipresencial: uma proposta baseada em sistemas de indicadores. Avaliação, Campinas/SP, v. 15, n. 3, p. 131-146, 2010. Disponível em: http:// submission.scielo.br/index.php/aval/article/view/28408/3477/. Acesso em: 14 jan. 2019.

BRASIL. Instituto Nacional de Estudos e Pesquisas Anísio Teixeira (Inep). Censo da Educação Superior: Sinopse Estatística 2002; 2016; 2018. Disponível em: http://inep. gov.br/sinopses-estatisticas-da-educacao-superior/. Acesso em: 10 jan. 2019.

BRASIL. Instituto Nacional de Estudos e Pesquisas Anísio Teixeira (Inep). Lei do Sistema Nacional de Avaliação da Educação Superior - Sinaes, n. 10.861, de 14 de abril de 2004. Disponível em: http://www.planalto.gov.br/ccivil_03/_ato2004-2006/2004/ lei/l10.861.htm/. Acesso em: 20 de jun. 2019.

BRASIL. Decreto 9.057, de 25 de maio de 2017. Regulamenta o artigo 80 da Lei no 9.394. Disponível em: http://www.planalto.gov.br/ccivil_03/_Ato2015-2018/2017/ Decreto/D9057.htm . Acesso em: 15 set. 2017.

CARLSEN, A.; HOLMBERG, C.; NEGHINA, C.; OWUSU-BOAMPONG, A. Closing the gap-Opportunities for distance education to benefit adult learners in higher education. Germany: Unesco Institute for Lifelong Learning (UIL), 2016. Disponível em: http://unesdoc.unesco.org/images/0024/002432/243264e.pdf/. Acesso em: 10 jul. 2018. 
DIAS SOBRINHO, J. Democratização, qualidade e Crise da Educação Superior: faces da exclusão e Limites da Inclusão. Revista Educação e Sociedade, Campinas, SP, v. 31, n. 113, p. 1223-1245, 2010.

DOURADO, L. F.; OLIVEIRA, J. F. de. A qualidade da educação: perspectivas e desafios. Cad. Cedes, Campinas, SP, v. 29, n. 78, p. 201-215, 2009.

DOURADO, L. F.; OLIVEIRA, J. F.de; SANTOS, C. A. A qualidade da educação: conceitos e definiçóes. Brasília: Instituto Nacional de Estudos e Pesquisas Educacionais Anísio Teixeira, 2007.

GÓMEZ, M. J. R. Indicadores, experiencias y problemas en la evaluación de la educación a distancia. In: RAMA, C. (Org.). Los problemas de la evaluación de la educación a distancia en América Latina y el Caribe. 2015. Disponível em: http://www. caled-ead.org/sites/default/files/files/libro-caled-2015.pdf/. Acesso em: 10 jan. 2019.

ICDE. International Council for Open and Distance Education. Quality models in online and open education around the globe: State of the art and recommendations. Project coordinator: EADTU - European Association of Distance Teaching Universities, 2015. Disponível em: https://www.icde.org/quality-models-in-online-andopen-education-around-the-globel. Acesso em: 15 mar. 2019.

LATCHEM, C. Garantia de qualidade na educaçáo a distância online. In: ZAWACKIRICHTER, O.; ANDERSON, T. (Org.). Educação a distância online: construindo uma agenda de pesquisa. São Paulo: Artesanato Educacional, 2015. p. 319-353.

\section{LIMA, D. C. B. P. Documento técnico contendo estudo analítico do processo de expansão} de EaD ocorrido no periodo 2002-2012, particularmente no que se refere aos cursos de formação de professores nas IES públicas e privadas. 2014. Produto 02. Projeto Conselho Nacional de Educação/Organização das Nações Unidas para a Educação, a Ciência e a Cultura. Disponível em: http://mecsrv125.mec.gov.br/index.php?option=com_ docman\&task=doc_download\&gid=16510\&Itemid=/. Acesso em: 26 mar. 2017.

LIMA, D. C. B. P.; ASSIS, L. M. de. Arena constitutiva da educação superior a distância: as regras do jogo e como o jogo é jogado. Revista Brasileira de Política e Administração da Educação, Brasília, v. 34, n. 1, p. 9-16, jan./abr. 2018. Disponível em: https://seer.ufrgs.br/rbpae/article/view/82461/48874/. Acesso em: 10 jun. 2019.

MALIK, S. K. Strategies for Maintaining Quality in Distance Higher Education. Turkish Online Journal os Distance Education, Eskisehir/Turkey, v. 16, n. 1, p. 238-248, 2015. Disponível em: https://files.eric.ed.gov/fulltext/EJ1092842.pdf/. Acesso em: 19 mar. 2019.

MILL, D.; OLIVEIRA, M. R. G. A educação a distância em pesquisas acadêmicas: uma análise bibliométrica em teses do campo educacional. Educar em revista, Curitiba, n. 4, p. 15-36, 2014. Disponível em: http://www.scielo.br/pdf/er/nspe4/0101-4358-eresp-04-00015.pdf/. Acesso em: 10 jun. 2019. 
MONTEIRO, A.; MOREIRA, J. A. O Blended Learning e a integração de sujeitos, tecnologias, modelos e estratégias de ensino-aprendizagem. In: MONTEIRO, A.; MOREIRA, J. A.; ALMEIDA, A. C.; LENCASTRE, J. A. (Orgs.). Blended Learning em contexto educativo: Perspectivas Teóricas e práticas de investigação. 2. ed., Santo Tirso/Portugal: De Facto Editores, 2013. p. 19-32.

MOROSINI, M. C. Qualidade na educação superior: tendências do século. Revista Estudos em avaliação educacional, São Paulo, v. 20, n. 43, p. 165-186, 2009. Disponível em: http://www.fcc.org.br/pesquisa/publicacoes/eae/arquivos/1487/1487.pdf/. Acesso em: 13 abr. 2018.

MOROSINI, M. C. et al. A qualidade da educação superior e o complexo exercício de propor indicadores. Revista Brasileira de Educação, Rio de Janeiro, v. 21, n. 64, p. 13-37, 2016.

NASCIMENTO, F. P. do; CARNIELLI, B. L. Educação a distância no Ensino Superior: Expansão com qualidade? Educação Temática Digital, Campinas, SP, v. 9, n. 1, p. 84-98, 2007. Disponível em: https://periodicos.sbu.unicamp.br/ojs/index.php/etd/ article/view/740/. Acesso em: 23 jan. 2019.

OLIVEIRA, J. F. de; LIMA, D. da C. B. P. Pós-Graduação e Educação a Distância: Novos fins, natureza e modus operandi em construção. In: CASTRO, A. et al. (Orgs.). Educação Superior em paises e regióes de Lingua Portuguesa: Desafios em Tempo de Crise. Lisboa: Educa, 2018. p. 215-242.

RAMA, C. Las complejidades de evaluar y acreditar la educación a distancia. In: CORBACHO, J. B. et al. (Org.). Los problemas de la evaluación de la educación a distancia en América Latina y el Caribe. Ecuador: Ediloja, 2015. p. 09-16.

RUBIN, Y. Modern E-learning: Qualitative education acessibility concep. In: European Association for Quality Assurance in Higher Education. Quality Assurance of E-learning. Finland, 2010. p. 18-27. Disponível em: https:/enqa.eu/indirme/papersand-reports/workshop-and-seminar/ENQA_wr_14.pdf/. Acesso em: 10 jan. 2019.

SABA, F. Métodos de estudo em educação a distância: revisão crítica de literatura recente selecionada. In: ZAWACKI-RICHTER, O.; ANDERSON, T. (Orgs.). Educação a distância online: construindo uma agenda de pesquisa. São Paulo: Artesanato Educacional, 2015. p. 153-173.

SANGRÀ, A.; VLACHOPOULOS, D.; CABRERA, N. Building an Inclusive Definition of E-Learning: an Approach to the Conceptual Framework. The International Review of Research in Open and Distance Learning, Athabasca/Canadá, v. 13, n. 2, p. 145-159, 2012. Disponível em: https://files.eric.ed.gov/fulltext/EJ983277. pdf. Acesso em: 10 jan. 2019. 
SHARPLES M.; ARNEDILLO-SÁNCHEZ, I.; MILRAD, M.; VAVOULA, G. Mobile Learning. In: BALACHEFF, N.; LUDVIGSEN, S.; DE JONG, T.; LAZONDER, A.; BARNES, S. (Orgs.). Technology-Enhanced Learning. Dordrecht: Springer, 2009. p. 233-249.

SINGH, B.; MISHRA, P. Quality Assurance in Distance Education. Journal of Applied Research in open and distance education, Bingley/United Kingdom, v. 24, n. 1, p. 85-92, 2016. Disponível em: https://www.researchgate.net/publication/319292174_Quality_ Assurance_In_Distance_Education/stats/. Acesso em: 10 nov. 2018.

SOUSA, L. S. de L.; LIMA, D. da C. B. P. Atos normativos do Conselho Federal de Educação e do Conselho Nacional de Educação: o desvelar da trajetória da educação superior a distância no Brasil. Eccos Revista Científica, São Paulo, n. 44, p. 143-158, 2017. Disponível em: http:/www4.uninove.br/ojs/index.php/eccos/article/ viewFile/7886/3652/. Acesso em: 10 mar. 2018.

VERSUTI, A. C. Uma comparação entre critérios de qualidade para avaliação de cursos a distância. Anais [...]. Congresso ABED 2008. Disponível em: http://www.abed. org.br/congresso2008/tc/5122008121658AM.pdf/. Acesso em: 10 jun. 2019.

VLACHOPOULOS, D. Assuring Quality in E-Learning Course Design: The Roadmap. International Review of Research in Open and Distributed Learning, Athabasca/Canadá, v. 17, n. 6, p. 183-215, 2016. Disponível em: https://files.eric. ed.gov/fulltext/EJ1122217.pdf. Acesso em: 6 nov. 2018.

Recebido em 20 set. 2019 / Aprovado em I7 dez. 2019

\section{Para referenciar este texto:}

LIMA, D. C. B. P.; ALONSO, K. M. Qualidade e educação a distância: do referencial teórico à sua proposição. EccoS - Revista Científica, São Paulo, n. 5I, eI5250, out./dez. 2019. Disponível em: https://doi.org/I0.5585/EccoS.n5I.I5250. 